\title{
A preliminary investigation of the formation of constituent questions in Karata (Nakh-Daghestanian)
}

\author{
Jérémy Pasquereau \& Rashidat Khalidova*
}

\begin{abstract}
This paper gives a first description of the formation of constituent questions in the understudied Karata language ( $\bar{k} i r \bar{L} i$ mac'i, Russian karatinskij jazyk). It argues that wh-questions in this language exhibit the characteristics predicted of type 4 languages by Cable 2010's theory.
\end{abstract}

Keywords. question particle; constituent questions; Karata; Caucasian

1. Introduction. The theory of constituent questions developed in Cable 2010 predicts 32 types of languages with respect to how constituent questions are formed. Several of those types have not been attested yet. In this paper, we propose that Karata ( $\overline{k i r} \bar{i} i$ mac ' $i$, Russian karatinskijjazyk), an Andic language of the Nakh-Daghestanian language family spoken in Daghestan, is an example of the until now unattested type $4 .^{2}$ The paper is organized as follows. Section 2 gives background on Karata in general and Karata wh-questions in particular, as well as background on Cable's theory of wh-questions. In section 3, we go through every property that a type 4 language is predicted to have and show that Karata has them.

2. Background. The purpose of this section is to give the background necessary to read the paper: first on the basic structure of Karata, then on wh-questions, and finally on Cable's 2010 theory of wh-questions.

2.1. BACKGROUND ON KARATA GRAMMAR. Concerning sentence structure, constituent order is very flexible and does not play any role in the expression of argument structure. Case marking and verb agreement are typical of ergative languages. Verbs agree in gender and number (i.e. in class) with the argument in the absolutive case (aka nominative case in the Caucasian linguistics tradition). In (1a), the A(gentive) argument or subject of the transitive construction bears ergative case morphology and the $\mathrm{P}$ (atientive) or object argument is in the unmarked nominative case (a.k.a. absolutive case). Example (1b) is an intransitive construction, accordingly, the S(ingle) argument or subject of the intransitive construction is in the unmarked absolutive case.

(1) Ergative alignment
a. $\tilde{1}$-su-1-da REFL-M0-ERG-INT
b-it'abis -a ho- $\check{\overline{\mathrm{s}}}$ u-1 ho-b hedela $\mathrm{N}$-settle-PF DEM-M0-ERG DEM-N thing
He solved the problem by himself.
b. že-b-eda b-it'abišset-e ho-b hedela
REFL-N-INT settle-PF DEM-N thing
This problem solved itself.

\footnotetext{
* Authors: Jérémy Pasquereau, University of Massachusetts Amherst, USA (jepasquer@gmail.com) \& Rashidat Khalidova, Pedagogical University of Daghestan, Russia (rashi@gmail.com).

2 The literature about Karata consists mainly of a grammatical sketch (Magomedbekova 1971) and a Karata-Russian dictionary with many examples (Magomedova \& Khalidova 2001). We have used the data from all those resources as well as field notes and elicited data, the second author being a native speaker of Karata.
} 
The verb $b$-it'abišata 'solve, settle' has a class prefix which agrees with the $\mathrm{S} / \mathrm{P}$ argument. There are two types of Karata verbs. Those beginning with a consonant, those beginning with a vowel which can themselves be divided into two subclasses: those with an agreement prefix reflecting the class of the noun in the nominative, those without. Note that whether a vowel-initial verb can take a agreement prefix or not is lexically specified. As far as suffixes are concerned, all verbs have the same suffixes except for the imperative suffix which makes a formal distinction between intransitive and transitive constructions (2).

(2) Examples of imperative or agreement

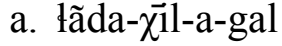
b-ah-a close-PROX-TPL3-ABL take-IMP(TR)
Remove it from the closest spot!

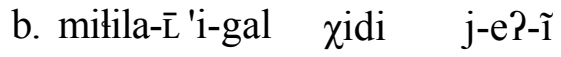 suno-TPL8-ABL away F-go-IMP(INTR)

Go away from the sun! (lit. from under the sun)

There are 7 grammatical cases (nominative, ergative/instrumental, genitive, animate genitive, dative, comitative, essive) in Table 1 . They are realized as suffixes attached directly to the nominative base or to an augmented form called 'oblique form'.

\begin{tabular}{ccccccc} 
NOM & ERG/INSTR & GEN & animate GEN & DAT & COM & ESS \\
$\varnothing$ & -1 & $-\overline{\mathrm{L}}$ & Class Marker & $-\mathrm{a}$ & $-\mathrm{k}$ 'el & $-\mathrm{ke}$ \\
& \multicolumn{4}{c}{ Table 1 1. Grammatical cases. }
\end{tabular}

The animate genitive case is reserved to mark animate possessors: it consists of the class marker reflecting the noun class that the possessed noun belongs to (3a). The other marker is used in all other cases (3b).

(3) Two genitives
a. imo-b
$\overline{\mathrm{q}}$ 'arz $\quad$ waša- $\check{\overline{\mathrm{s}}} \mathrm{u}-1$
herc'-e
father $\left[\right.$ GEN]-N debt boy-M $\mathrm{M}_{0}-\mathrm{ERG}$
pay_off-PF
b. peči- $\overline{\mathrm{L}}$
curi-1 tastar
вizi- $\overline{\mathrm{W}} \mathrm{w}-\overline{\mathrm{a}}$
stove-GEN smoke $_{0}$-ERG curtain
dirt-VBZ-CAUS.PF
The smoke of the stove made the curtain dirty.

Spatial cases are made of 2 formatives: a topological marker (TPL), which encodes the location of the figure with respect to a ground ${ }^{3}$ (Talmy 1972), and a directional marker which encodes whether the figure moves or not (DIR). In English for instance, complex prepositions like onto can be decomposed into the topological marker on 'TPL' and the directional marker to 'DIR'. Karata has 8 topological markers x 3 directional markers, potentially forming 24 spatial cases, of which four are not attested (those are marked n.a. in Table 2). It is difficult to label each topological marker with one semantic value given the many different values that each of those markers

\footnotetext{
${ }^{3}$ The notions of Figure and Ground were introduced in Talmy 1972 to refer, respectively, to the located and to the locating entity (see Fortis 2010).
} 
can take and the many different distinctions that are not lexicalized in English (see Pasquereau 2010 for more information).

\begin{tabular}{|c|c|c|c|c|c|c|c|c|}
\hline & $\mathrm{TPL}_{1}$ & $\mathrm{TPL}_{2}$ & $\mathrm{TPL}_{3}$ & $\mathrm{TPL}_{4}$ & $\mathrm{TPL}_{5}$ & $\mathrm{TPL}_{6}$ & $\mathrm{TPL}_{7}$ & $\mathrm{TPL}_{8}$ \\
\hline LOC & -č'o & $-\mathrm{L}^{\prime} \mathrm{a}$ & $-a$ & n.a. & $-\bar{q}$ & $-i$ & $-\overline{\mathrm{L}} \mathrm{i}$ & $-\bar{L}^{\prime}{ }^{\circ}$ \\
\hline ALL & n.a. & -L'a-r & $-a-r$ & $-\chi \mathrm{a}-\mathrm{r}-$ & n.a. & $-i-r$ & $-\overline{\mathrm{L}} \mathrm{i}-\mathrm{r}$ & $-\overline{\mathrm{L}} \mathrm{\prime} \mathrm{i}-\mathrm{r}$ \\
\hline $\mathrm{ABL}$ & -č'o-gal & -L'a-gal & $\begin{array}{r}\text {-a-gal } \\
\text { Table } 2 .\end{array}$ & $\frac{\text { n.a. }}{\text { atial c }}$ & $\begin{array}{l}\text {-q̄i-gal } \\
\text { suffixes }\end{array}$ & -i-gal & -L̄i-gal & $-\bar{L}$ 'i-gal \\
\hline
\end{tabular}

Below in (4), we give an example of topological marker 7 in each of the three directional cases. This case is used to locate a figure within a liquid.
a. č́'irq̄'aj hane
$\overline{\mathrm{l}} \tilde{\mathrm{e}}-\overline{\mathrm{L}} \mathrm{i}$
$\mathrm{bac}^{\mathrm{w}}-\overline{\mathrm{a}}$
Chirkai village
water0-TPL 7 [LOC] flood-PF
The village of Chirkai flooded. (lit. got plunged in water ${ }^{4}$ )
b kař ì-īi-r
$\bar{c}$ 'ãji t'ama
porridge-TPL $\mathrm{T}_{7}$-ALL salt throw.IMP
Put salt in the porridge!
c. $\bar{l}$ ẽji-L̄i-gal b-ō̄ -e herk'a-m č'ina
water0-TPL $\mathrm{L}_{7}$-ABL N-extract-PF big-N log

They extracted a big log from the water.

(lit. I/you/he/she/we/y'all/they extracted a big log from inside the water.)

Spatial cases are also used more abstractly as part of the argument structure of predicates (Pasquereau 2011). There are 5 noun classes in Karata: 3 in the singular (masculine, feminine, neuter) and 2 in the plural (human, neuter) as shown in Table 3. The class of a noun is reflected in the Class Marker (CM) used for agreement.

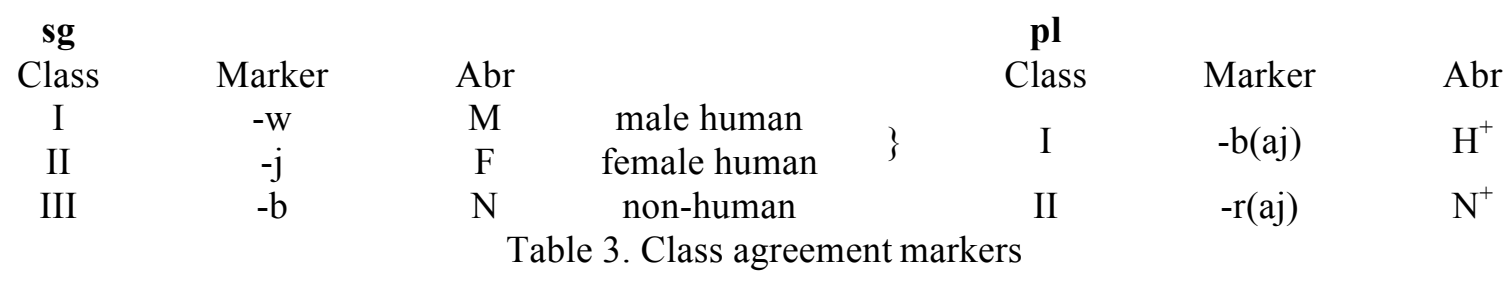

The head bears number and case morphology. There are many plural endings and it must be learnt for each noun. In (5) is schematized the maximal structure of a noun in Karata.

$$
\begin{aligned}
& \text { Noun structure } \\
& \text { noun[NOMINATIVE] }(+ \text { PL })(+ \text { OBL })+\text { case }
\end{aligned}
$$

For instance, the ergative plural of mak'e 'child' is formed by adding the plural suffix $-i$, then the human plural oblique formative $l o$, to which is added the ergative case marker $l$. Note that oblique stem formatives are quite varied. In fact only nouns belonging to one of the 'human'

\footnotetext{
${ }^{4}$ In Karata, locative is used for movement with contact between the ground and the holder of the figure, whereas allative is used if there is no contact. In (6b) for example, there is no contact between the hand that holds the salt and the porridge.
} 
classes take semantically-motivated oblique markers, as in (6a) where lo is the oblique marker for nouns belonging to the human plural class. Nouns belonging to non-human classes how- ever take a variety of oblique markers which have to be learned. In (6b) for instance, the citation/nominative form for the word 'color' is $\bar{L}$ 'ere but case suffixes are added to the oblique form $\bar{L}^{\prime}$ era which we gloss 'color 0 '.
a. mak'-i-lo-1
mak'e 'child'
child-PL-H+-ERG
b. $\overline{\mathrm{L}}$ 'era- $\overline{\mathrm{L}}$
$\overline{\mathrm{L}}$ 'ere 'color'
color ${ }_{0}$-GEN

2.2. BACKGROUND ONKARATA WH-QUESTIONS. In order to ask a wh-question in Karata, three ingredients are necessary: a wh-word, the Question particle- $(o) l(e)$, and the main verb of the question must be in the participial form ( $7 a$ and $7 b)$ except in the future where the finite form is the oneused $(7 \mathrm{c})$.
a. hed-ol suni
$\mathrm{b}-\mathrm{oL}-\mathrm{o}-\mathrm{b}$ ?
past
thing-Q yesterday
N-happen-PTCP.PF-N
What happened yesterday?
b. hin̄̌ do-b maršrutka-1 b-o?-ĩd-o-b bazar-L'a-r?
which-N marshrutka-Q N-go-IPF-PTCP-N bazar-TPL ${ }_{2}$-ALL
Which marshrutka ${ }^{5}$ goes to the bazar?
c. hed-ol den-a $\overline{\mathrm{q}}$ 'ama-s ?
thing-Q 1SG-ERG eat-FUT
What will I eat?

Karata has the wh-words in (8).

(8)
Karata wh-words
hede 'what'
hinšda 'how'
heme 'who'
hinda 'when'
to ${ }^{6}$ 'who'
hense 'why'
hinštob 'which'
heta 'why, what for'
hinge 'where/to where'
čãc'e 'how many times'
hindir 'to where'
čami 'how much/many'
hingal 'from where'

A number of constraints apply to the distribution of Q, they will be described in section 3 . Let me point out now though that there is a correlation between the position of $\mathrm{Q}$ and the verb which is marked non-finite. Both indicate the scope of the question. The example in (9a) is a matrix question: the verb in the participial form, as is made obvious by the presence of an

\footnotetext{
5 A marshrutka is a fixed-route minibus.

6 There are two words for 'who'. We have not enquired fully into the difference between them. My elicitation so far suggests that in a suppletive paradigm: heme can only be in the absolutive, and all other cases are derived regularly from to. There is one irregular case with this form: the ergative is not the expected *tol but tola.
} 
agreement suffix, is the matrix verb ${ }^{7}$, the $Q$ particle is at the edge of the embedded clause. The example be- comes unacceptable if $\mathrm{Q}$ is in the embedded clause with the embedding verb bearing participial morphology (9b).
a. [hede ho- $\stackrel{\check{S}}{u}-1 \quad$ b-ek $-e-\bar{L}$ 'e]-1 idja-j ho-j? [thing DEM-M ${ }_{0}$-ERG N-give-PF-QUOT ${ }^{8}$ ]-Q COP-PTCP.F DEM-F What does she think he gave?
b. *[hed-ol ho- $\check{\overline{\mathrm{s}}} \mathrm{u}-1 \quad \mathrm{~b}-\mathrm{e} \overline{\mathrm{k}}-\mathrm{e}-\overline{\mathrm{L}}$ 'e] $\quad$ idja-j ho-j?
[thing-Q DEM-M ${ }_{0}$-ERG N-give-PF-QUOT] COP-PTCP.F DEM-F
Int. What does she think he gave?

In (10a), the verb in the participial form is 'give' in the embedded clause and Q is on the whword. The example becomes unacceptable if, keeping the embedded verb in the participial form, $\mathrm{Q}$ is in the matrix clause (10b).
a. [hed-ol ho- $\check{\bar{s}} \mathrm{u}-1$
b-ek $-o-b-\bar{L}$ 'e]
idja ho-j.
[thing-Q DEM-M ${ }_{0}$-ERG
N-give-PTCP.PF-N-QUOT] COP DEM-F
She is thinking about what he gave.
b. $*$ hede ho- $\check{\bar{s}} \mathrm{u}-1$
b-e $\overline{\mathrm{k}}-\mathrm{o}-\mathrm{b}-\overline{\mathrm{L}}$ 'e]-1
idja ho-j.
[thing DEM-M ${ }_{0}$-ERG N-give-PTCP.PF-N-QUOT]-Q COP DEM-F
Int. She is thinking about what he gave.

We now turn to Cable 2010's theory of constituent questions.

2.3. BACKGROUND ON CABLE'S TYPOLOGY. In his 2010 book, Cable argues that the crosslinguistic typology of wh-questions is captured by the combined values of 5 bivalent parameters (11).

(11) Parameter values for type 3 languages, e.g. Tlingit (Cable 2010)

Parameter 1: Pronounced Q vs. Null Q?

Parameter 2: Q-projection vs. Q-adjunction?

Parameter 3: overt Q-movement vs. covert Q-movement?

Parameter 4: Does Q agree with the wh-word? Yes / No

Parameter 5: Multiple wh-questions: multiple Q or single Q?

According to Cable 2010, all languages have a Q particle: in some it is overt, in others it is covert (parameter 1).

\footnotetext{
${ }^{7}$ The copula idja can be used on its own with the meaning 'think'.

${ }^{8}$ We gloss the morpheme $\bar{L}^{\prime} e$ 'quot' for 'quotative' since this morpheme is used to introduce reported speech (it is etymologically related to the verb $k e \bar{L}$ ' $a \tilde{t} a$ 'speak'). Its use is broader though.
} 


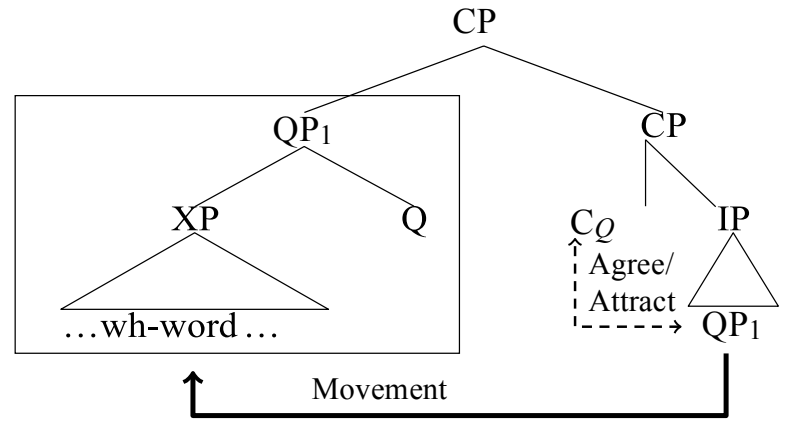

The second parameter concerns the syntactic relation of Q to the phrase XP that contains the wh- word. We give examples in section 3 that this phrase can be as small as the wh-word itself but can also be bigger, in which case the Q particle is separated from the wh-word. In some languages, QP is adjoined to the XP containing the wh-word, whereas in others Q takes it as its complement, i.e. the wh-word is in the QP constituent. The value this parameter takes has important consequences for properties of wh-questions given that it interacts with parameters 3, 4, and 5. For example, under this theory, a wh-fronting language is a language whose QP contains the wh-word and moves overtly. Parameter 4 captures an important difference between English and Karata which we illustrate in section 3.4. Finally, parameter 5 captures that some languages do not allow more than one $\mathrm{Q}$ no matter how many wh-words the question contains, whereas oth- ers will allow up to as many Qs as the question contains.

In order to look at the Karata data, we make the (comparative) hypothesis (Haspelmath 2014) that the Q particle -ol in Karata constituent questions behaves like the Tlingit Q particle sá studied by Cable. The result of our study so far suggests that it behaves exactly like Tlingit on parameters 1-4 and differs from it on parameter 5 since it allows multiple questions with just one occurrence of Q. Such a language is predicted to exist (as 'type 4') but was not attested until now.

3. Karata is a type 4 language. A type 4 language in Cable's typology has the following properties: Q is overt, Q projects and takes the XP containing the wh-word as its complement, QP moves overtly as a result of agree/attract with $\mathrm{C} Q$, the wh-word does not agree with $\mathrm{Q}$ (unlike English), and multiple wh-questions use one Q. This is summarized in (13).

Parameter values for type 4 languages, e.g. Karata

Parameter 1: Pronounced Q vs. Null Q?

Parameter 2: Q-projection vs. Q-adjunction?

Parameter 3: overt Q-movement vs. covert Q-movement?

Parameter 4: Does Q agree with the wh-word? Yes / No

Parameter 5: Multiple wh-questions: multiple Q or single Q?

In what follows we illustrate each parameter with Karata data.

3.1. THE QUESTION PARTICLE IS OBLIGATORY. As the minimal pair in (14) shows, Q must be overtly realized or else, the construction is not acceptable. 

a. men-a hing-ol Surmi ge-da idja-b ?
2SG-ERG where-Q life do-IPF COP-PTCP.N
Where do you live?
b.*men-a hinge Surmi ge-da idja-b ?
2SG-ERG where life DO-IPF COP-PTCP.N
Int. Where do you live?

3.2. Q MUST C-COMMAND THE WH-WORD. Q can appear to the right of any word in the constituent that contains the wh-word (15): in a. Q occurs at the edge of a constituent that contains only the wh-word, in b. it appears at the edge of the verb phrase.
a. men-a hing-ol Surmi ge-da idja-b ?
2SG-ERG where-Q life DO-IPF COP-PTCP.N
Where do you live?
b. men-a hinge Surmi ge-da-l idja-b ?
2SG-ERG where life do-IPF-Q COP-PTCP.N
Where do you live?

But it must c-command it: in (16), Q is placed to the right of the wh-word hinge 'where' but on the object Surmi 'life', a noun which does not c-command the wh-word, this yields unacceptability.
* men-a hinge Surmi-l ge-da idja-b?
2SG-ERG where life-Q do-IPF COP-PTCP.N
Int. Where do you live?

3.3. WH-WORDS IN THE PERIPHERY OF THE QUESTION. If QP moves overtly, we expect wh-words to appear at the periphery of the clause. As already mentioned, word order in Karata is very flexi- ble, but there are a few facts that suggest that movement occurs. First, the wh-word must precede the main predicate. This is expected if Q projects and moves (c.f. 17a and 17b).

(17) Questions
a. *men-a $\overline{\mathrm{q}}$ 'amas
hed-ol ā̄i?
$* \mathrm{~S}$ V O
2SG-ERG eat-FUT
thing-Q tomorrow
Int. What will you eat tomorrow?
b men-a hed-ol
$\overline{\mathrm{q}}$ 'amas̄ à̄i?
S O V
2SG-ERG thing-Q eat-FUT tomorrow
What will you eat tomorrow?

It could be that the post- $\mathrm{V}$ position is reserved for nouns that have properties which whwords lack like definiteness but this is not the case since indefinites can appear post-verbally (18a).
Assertions
a. men-a 2SG-ERG eat-FUT thing-INDEF q̄'amās hede-bik'u
à̄i. S V O
You'll eat something tomorrow.
tomorrow 

b. men-a
hede-bik'u $\bar{q}$ 'amas̄
à̄i.
S O V
2SG-ERG thing-INDEF eat-FUT
tomorrow
You'll eat something tomorrow.

Secondly, there is evidence that if there is a phrase to the left of the wh-word, it is interpreted as a topic. Placement of an phrase before the wh-word creates a structure with special discourse prop- erties: there is reason to think that the phrase preceding the wh-phrase is interpreted as a topic.

A core property of 'topics' is that they can only be denoted by referential expressions ( $\mathrm{Li}$ 1976). If QP moves overtly in Karata, we expect the wh-word to be in the left periphery of the syntactic structure and we expect that any phrase to its left will be topical. We would therefore expect that no indefinite can occur to the left of a wh-word in Karaa. This seems to be the case (cf 19a and 19b).
a. hem-ol hindi-r-ৎagi w-o?-ã-č'-o-w?
who-Q where-ALL-any M-go-PF-NEG-PTCP.PF-M
Who will go nowhere? (lit. who will not go anywhere?)
b.*hindi-r-Sagi hem-ol w-o?-ã-č'-o-w?
where-ALL-any who-Q M-GO-PF-NEG-PTCP.PF-M
Int. Who will go nowhere?

A final suggestive piece of evidence is the (Russian) translations offered by speakers for ques- tions like (20) with a dislocated topic.

$$
\begin{aligned}
& \text { duwa hem-ol L'ab-o-b? } \\
& 2 \mathrm{SG}_{0} \text {.DAT who-Q love-PF.PTCP-N } \\
& \text { You, who do you love? }
\end{aligned}
$$

These data follow from the view that any material preceding the wh-operator of a Karata wh- question must be construed as a discourse topic, which follows if the wh-word is leftperipheral as a result of QP movement.

3.4. CQ AND QP AGREE, Q AND WH-WORD DO NOT. Here we want to show that under the hypothesis that an agreement dependency holds between the question-marked complementizer $\mathrm{C} Q$ and the QP, an acceptability asymmetry follows. First, observe that (21a) where the QP hedol 'what' is contained within a relative clause is not acceptable and that $(21 \mathrm{~b})$, where the QP is now the whole relative clause, is acceptable. Those observations follow under the assumption that no agreement is possible across an island boundary.

(21) Q and CQ agree
a. ${ }^{*}$ [hed-ol b-aL'-ido-j jaše] Sumar-ja L'abo-j $\quad \mathrm{C}_{Q}$ ? thing-Q N-wear-IPF.PTCP-F girl Omar-DAT love-PF.PTCP-F Int. Omar loves the girl who is wearing what?
b. [hede b-aL'-ido-j jaše]-1 Sumar-ja L'abo-j $\mathrm{C}_{Q}$ ? thing N-wear-IPF.PTCP-F girl-Q Omar-DAT love-PF.PTCP-F
Omar loves the girl who is wearing what?


On the other hand, notice that if $\mathrm{Q}$ and the wh-word hede 'thing/what' did agree, the previous example (21b) repeated in (22) would not be acceptable under the same assumption that agreement is not possible across a syntactic island boundary.

$$
\begin{aligned}
& \text { No agreement between Q and wh-word in Karata } \\
& \text { [hede b-aL'-ido-j jaše]-l Gumar-ja L'abo-j? } \\
& \text { thing N-wear-IPF.PTCP-F girl-Q Omar-DAT love-PF.PTCP-F } \\
& \text { Omar loves the girl who is wearing what? }
\end{aligned}
$$

We conclude that, under the assumption that agreement is not possible across a relative clause boundary, $\mathrm{Q}$ and $\mathrm{C} Q$ must agree in Karata whereas $\mathrm{Q}$ and the wh-word do not agree.

Notice things are different in English wh-questions: $Q$ and the wh-word must agree and since there can be no agreement across a relative clause boundary, the construction in (23) is not acceptable (Cable, 2010, p. 147).

Agreement between Q and wh-word in English

* [The girl who is wearing what]-Q does Omar love $\mathrm{C}_{Q}$ ?

In summary, the evidence that $\mathrm{Q}$ and the wh-word do not agree comes from the fact that islands (inside QP) can be moved/pied-piped (unlike in languages with wh/Q agreement, e.g. English).

3.5. MultiPLE WH-QUeSTIONS. If Karata is an instance of a type 4 language, multiple whquestions should be formed with just one $\mathrm{Q}$ and not exhibit superiority effects. This is what we found: in (24a), the wh-words corresponding to the subject and object arguments occur in the canonical Karata word order (SOV) and the question particle occurs at the right edge of the object wh-word. In (24b), the wh-words are reversed and the Q particle appears at the right edge of the subject wh-word.

(24) [wh-word wh-word]-Q, no superiority effects
a. tola hed-ol
bahała idja-b?
who.ERG what-Q
buy COP.PTCP-N
Who will buy what?
b. hede tola-1
bahała idja-b?
what who.ERG-Q
buy COP.PTCP-N

Karata is also an instance of a type 3 language: there can be as many Qs as there are whwords but in that case, superiority effects obtain (25b). 
3.6. QP INTERVENTION CONDITION. Further patterns follow. Cable defines a condition (26) to capture a pattern evinced by a number of languages.

The QP intervention condition

A QP cannot intervene between a functional head and an [XP] selected by it.

$\mathrm{Q}$ can be at the right edge of an embedded clause but not of a matrix clause. This asymmetry follows from the QP condition. QP intervenes between $\mathrm{C}_{Q}$ and [IP] (or $\square$ and [VP])

(27) Q cannot be at the right edge of a matrix clause

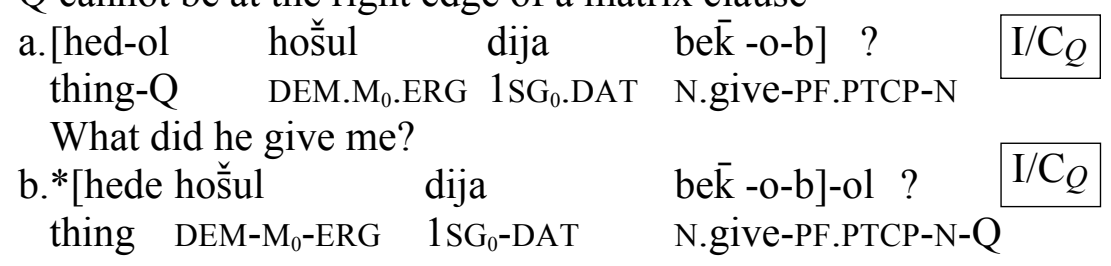

QP does not intervene between V, which is not a functional head, and its Compl, [CP] correctly predicting that $\mathrm{Q}$ can be at the right edge of an embedded clause.

\begin{tabular}{|c|c|c|c|c|}
\hline Thec & ho ̌̌sl & bek̄ e-L̄ 'e]-1 & idja-i & ho-j ? \\
\hline thing & DEM.M.M 0 ERG & N.give.PF-QUOT-Q & COP-PTCP-F & DEM-F \\
\hline
\end{tabular}

The fact that $\mathrm{Q}$ intervenes between, e.g. a $\mathrm{P}$ and its [NP] complement, is captured by that condition if $\mathrm{Q}$ projects and takes $[N P \ldots$ wh-word ...] as a complement.
a. [ło-č́o]
kaPa $-1 \overline{\mathrm{q}}^{\prime \mathrm{w}}$ apa
idja-b ?
who-TPL 1 LOC]
on-Q hat
COP-PTCP.N
Who is the hat on?
b. * [ło-čo]-1
kaPa $\quad \overline{\mathrm{q}}^{\prime \mathbf{w}}$ apa
idja-b ?
who-TPL1[LOC]-Q
on hat
COP-PTCP.N

Our preliminary study suggests that the 5 parameters hypothesized in Cable 2010 are at work in the formation of wh-questions in Karata too. Nevertheless, this is not to say that this is all there is to say about wh-questions in this language. In fact, our preliminary examination has raised many questions which need further investigation. For instance, while it is possible to view the Karata facts in 3.3 as supporting the view that Karata has wh-movement, such a conclusion faces sev- eral potential challenges which need further investigation. First, it has been noted that in Nakh- Daghestanian languages focused items in general precede the main predicate (Van den Berg 2005), thus it is possible that the observations in 3.3 follow from this general constraint rather than from a constituent question-specific one. Secondly, if wh-words really do front, we might expect to find long-distance wh-movement. Given that Karata is most naturally rightbranching, it is more difficult to see (than in a left branching language). Still in our small corpus of written text, we have not found evidence that this is possible.

4. Conclusion. The hypothesis that Karata examplifies the (until now unattested) type 4 (and 3) language(s) in Cable's typology (2010) correctly predicts the behavior of Karata wh-questions. As pointed out above, many questions need further investigation but we hope that we have at 
least established a basis. In particular we would like to understand the mechanism that links the form of the verb to the presence of the Q -ol as well as the difference with another question particle used in wh-question -la which does not require the verb to be in the participial form.

Glosses: $\mathrm{H}+$ : human plural, $\mathrm{N}+$ : non-human plural, $\mathrm{X} 0$ : oblique form of $\mathrm{X}, \mathrm{ABL}$ : ablative, ADD: additive, ADV: adverb, ALL: allative, CAUS: causative, COP: copula, COM: commitative, CVB: converb, DAT: dative, DEM: demonstrative, ERG: ergative, F: feminine, FUT: future, GEN: genitive, IMP: imperative, IMP(INTR): intransitive imperative, IMP(TR): transitive imperative, IPF: imperfective, INF: infinitival, INT: intensive, LOC: locative, LOG: logophoric, M: masculine, MSD: masdar, NEG: negation, NOM: nominative, N: neuter, PTCP: participle, PF: perfective, PL: plural, PROH: prohibitive, PROX: proximal, Q: question particle, QUOT: quotative, REFL: reflexive, SG: singular, SPCVB: specialized converb , TPL: topological, VBZ: verbalizer

\section{References}

Cable, S. 2010. The grammar of $Q$. Oxford University Press.

Fortis, J. M. 2010. Space in language. (Course given at Leipzig Summer School 2010)

Haspelmath, M. 2014. Descriptive hypothesis testing is distinct from comparative hypothesis testing: commentary on Davis, Gillon, and Matthewson. Language, 90(4), 250-257.

Li, C. 1976. Subject and Topic. New York: Academic Press.

Magomedbekova, P. 1971. Karatinskij jazyk: grammatičeskij očerk, teksty, slovar' (karata: grammar sketch, texts, dictionary). Mecniereba: Tbilisi.

Magomedova, P. T., \& Khalidova, R. S. 2001. Karatinsko-ruskij slovar'. (karata-russian dictionary.). Makhachkala: Dagestanskij Nauchnyj Centr Rossiskoj Akademii Nauk.

Pasquereau, J. 2010. Spatial cases in Karata: spatial and non-spatial uses (Master's thesis, Université Lyon II). Retrieved from https://jeremy-pasquereau.jimdo.com/app/ download/14488470925/MEMOIRE(06.09).pdf?t=1493938406

Pasquereau, J. 2011. Valency in Karata: a preliminary study (Master's thesis, Université Lyon II). Retrieved from https://jeremypasquereau.jimdo.com/app/download/ 14488445625/Me\%CC\%81moireM2.pdf? $\mathrm{t}=1493938406$

Talmy, L. 1972. Semantic Structure in English and Atsugewi (Unpublished doctoral dissertation). University of California, Berkeley.

Van den Berg, H. 2005. The East-Caucasian Language Family. Lingua(115), 147190. 